\title{
Application of BP Neural Network Model in the Evaluation of Urban Land Intensive Utilization
}

\author{
Yang Xiongfei ${ }^{1, *}$, Yuan Xitun ${ }^{1}$, Wen YongXiao ${ }^{1}$, Zhang Hang ${ }^{1}$, Han $\mathrm{Qi}^{1}$ \\ ${ }^{1}$ Department of Surveying and Mapping Engineering, Xi'an University of Science and Technology, Xi'an City, Shaanxi Province,China
}

\begin{abstract}
Using BP neural network model to analyze the urban land development status of Zhengzhou City from 2013 to 2017, the evaluation grades are divided into over-utilization, intensive use, moderate utilization and extensive utilization, and from the land input intensity, land use intensity and a total of nine indicators were selected for evaluation in three aspects of land output benefits. The results show that the urban land intensive degree of Zhengzhou City during the five years from 2013 to 2017 is $0.3039,0.5118$, $0.6189,0.6914,0.8509$, and the intensive degree is gradually increased every year. The degree of intensive use is gradually increased every year, the evaluation level has risen from extensive use to intensive use, and the intensity of land intensive use has continued to increase.
\end{abstract}

\section{Introduction}

Since the reform and opening up, China's economic level has achieved rapid growth, of which labor and land are important forces for economic growth. In particular, the rapid expansion of urban scale in recent years will inevitably accelerate the expansion of urban construction area and urban built-up area. However, most urban expansions are at the expense of arable land resources and ecological land, and one-sided pursuit of urban scale and economic growth, lacking long-term Planning has caused serious problems such as irrational urban land use structure and spatial layout, extensive use of land, and repeated construction of urban jurisdictions, overlapping functions, and low input-output efficiency ${ }^{[1]}$. These land issues have been highly valued by the state management departments, and law and regulations have been continuously promulgated, requiring strict conservation and intensive use of existing land resources, and actively revitalizing the extensive use of land within the city. Instead of targeting quantity, it is necessary to strengthen land intensiveness.Further improve the level of intensive use of urban land.

In traditional land intensive use evaluation, the DPSIR model is usually used to evaluate the degree of intensiveness. It is through the causal chain of driving force--pressure--state--influence--response. But this model includes human subjectivity when determining the weights of evaluation factors, which leads to uncertainty errors in the final results. However, the Artificial Neural Network (ANN) can greatly reduce the influence of human factors, and hundreds of models have been continuously developed, among which Back-Propagation artificial neural network (BP network) due to its excellent non-linear mapping ability, it is not affected by human factors, it can be trained through a large number of sample data, and the weights can be automatically modified to make the final result converge within a reasonable error range, so it has been widely used ${ }^{[2]-[4]}$.

\section{Overview of Zhengzhou City Development}

Zhengzhou is the capital of Henan Province and the political, economic, cultural and educational center of the whole province. As of the end of 2017, Zhengzhou had a total population of 9.881 million, a built-up area of 500.8, and an urban construction land area of 486.5 , of which industrial land was 43.5 , accounting for $9 \%$, logistics and storage land was 19.5 , accounting for $4 \%$, and residential land was $124.625 \%$, the land area for transportation facilities is 89.9 , accounting for $18 \%$, the land area for public management facilities is 90.6 , accounting for $18 \%$, the green area is 100.5 , accounting for $21 \%$, and the special land is 30.5 , accounting for $5 \%$.

\section{Overview of BP neural network}

The BP neural network was first proposed by the team of Rumelhart and McCelland in 1986.Itdoes not need to solve the mathematical relationship of the current mapping relationship in advance. In the network learning, it can store and record a large number of input-output mapping relationships to reflect The model relationship is a complex network structure formed by the interconnection of a large number of neuron nodes, and a mathematical model that can reflect the structure and function of human brain neurons ${ }^{[5]-[8]}$. The network model is composed of input layer, hidden layer and 
output layer, as shown in Figure 1.

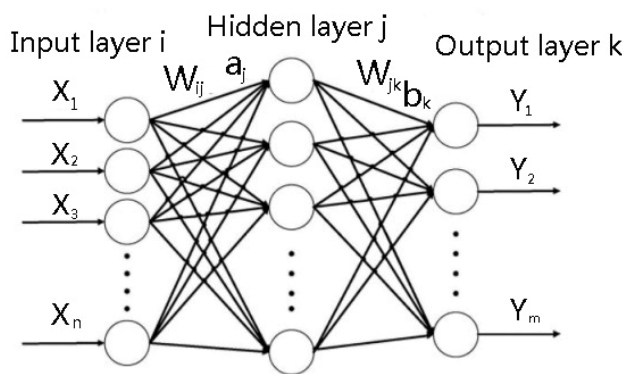

Figure 1 Basic structure of artificial neural network

The working principle is that the input layer first receives external data and transmits it to the intermediate hidden layer. The hidden layer can be divided into single layer and multiple layers, and finally passed to the output layer, which is the forward transfer of the working process. In the process of forward transfer of data, the weight threshold of the model is fixed, so different layers can only be affected by the upper layer. If the data error obtained by the final output layer does not meet the requirements, it will carry out direction transfer, automatically feedback and adjust the weight threshold in the network model, and then pass it to the input layer in turn, and then forward it until the final result meets the requirements.

\section{Examples of land intensive evaluation based on BP neural network}

\subsection{Data sources}

The data comes from "Henan Statistical Yearbook" (2014-2018), "Zhengzhou Statistical Yearbook" (2014-2018), "Construction Land Conservation and Intensive Utilization Evaluation Regulations" (TD/T 1018-2008), "Urban Land Classification and Planning and Construction" Land Use Standards (GBJ137-90), Land Management Industry Standards of the People's Republic of China, etc.

\subsection{Evaluation index selection}

The urban land system itself is a complex system engineering, which contains a series of variable factors such as society, economy, culture, etc. It is also difficult to use a set of fixed indicators as an evaluation system for these variable factors. Therefore, when selecting evaluation indicators, it is necessary to screen out the factors that have a greater impact on the intensive use of urban land and have a higher comprehensiveness, and select representative indicators among them. This can not only simplify the model, but also more objectively reflect the overall city. Intensive utilization status. In this paper, by referring to relevant data and research, a total of 9 indicators are selected from the three aspects of land input intensity, land use intensity and land output benefit to evaluate the indicators ${ }^{[9]-[12]}$ (Table 1).

Table 1 Evaluation index system of urban land intensive use

\begin{tabular}{|c|c|c|}
\hline Target layer & Element layer & Index layer \\
\hline \multirow{9}{*}{$\begin{array}{l}\text { Land Intensive } \\
\text { Utilization } \\
\text { Evaluation Index } \\
\text { System }\end{array}$} & & Park green area per capita $I_{0}$ \\
\hline & Land input intensity & Urban road area per capita $I_{1}$ \\
\hline & \multirow{4}{*}{ Land use intensity } & Number of buses per 10,000 people in the urban area $I_{2}$ \\
\hline & & The population density $I_{3}$ \\
\hline & & Per capita living area of urban residents $I_{4}$ \\
\hline & & Number of beds per 10,000 people $I_{5}$ \\
\hline & \multirow{3}{*}{ Land output benefit } & GDP per capita $I_{6}$ \\
\hline & & GDP per land $I_{7}$ \\
\hline & & Per capita disposable income of urban residents $I_{8}$ \\
\hline
\end{tabular}

\subsection{Classification of evaluation grades}

The classification of evaluation grades is a scientific expression of the evaluation results of the area. It is based on the actual situation of intensive land use in Zhengzhou City and the evaluation experience of other cities of the same type, and is based on the construction land conservation in the "People's Republic of China Land Management Industry Standards" Intensive utilization evaluation procedures divide the city's evaluation levels into four levels: over-utilization, intensive utilization, moderate utilization and extensive utilization (Table 2). 
Table 2 Urban land intensive use level registration

\begin{tabular}{ccccc}
\hline Grade & Extensive use & Moderate use & Intensive use & Overuse \\
\hline Range & $\mathrm{Y} \leqq 0.3$ & $0.3<\mathrm{Y} \leqq 0.6$ & $0.6<\mathrm{Y} \leqq 0.9$ & $0.9<\mathrm{Y}$ \\
\hline
\end{tabular}

Next, establish the evaluation index grading standard in accordance with national standards and with reference to other similar city standards. Because a large amount of sample data is needed in the training of BP neural network, it is difficult to calculate accurate results with only a few standard value samples, so it is also necessary to linearly interpolate the sample values to obtain a data set with more samples .
Finally, the collected raw data will be summarized. Because the unit and nature of each evaluation index are different, its index is not compatible with each other, which is not convenient for later calculations, so it is necessary to map all the data to a specific interval. , In general, it is normalized to $[-1,1]$, that is, dimensionless processing is performed. (Table 3) The calculation formula is as follows:

Table 3 Evaluation standard values of BP network for intensive land use in Zhengzhou

\begin{tabular}{ccccc}
\hline Grade & Overuse & Intensive use & Moderate use & Extensive use \\
\hline$I_{0}$ & -0.09 & -0.45 & -0.60 & -0.82 \\
\hline$I_{1}$ & -0.13 & -0.36 & -0.50 & -0.83 \\
\hline$I_{2}$ & -0.16 & -0.45 & -0.60 & -0.89 \\
\hline$I_{3}$ & -0.09 & -0.45 & -0.58 & -0.73 \\
\hline$I_{4}$ & -0.06 & -0.39 & -0.54 & -0.82 \\
\hline$I_{5}$ & -0.09 & -0.35 & -0.52 & -0.91 \\
\hline$I_{6}$ & -0.16 & -0.48 & -0.62 & -0.89 \\
\hline$I_{7}$ & -0.03 & -0.41 & -0.58 & -0.90 \\
\hline$I_{8}$ & -0.10 & -0.52 & -0.69 & -0.94 \\
\hline
\end{tabular}

$$
Y_{i j}=\frac{X_{i j}-X_{\min }}{X_{\max }-X_{\min }} \quad \text { Positive index }
$$

In the above formula, $Y_{\mathrm{ij}}$ is the standard score of the indicator; $X_{\mathrm{ij}}$ is the indicator value before processing; $X_{\max }$ is the maximum value of the indicator before processing; $X_{\min }$ is the minimum value of the indicator before processing; $i$ is the number of samples; $j$ is the number of indicators.

\subsection{Implementation of BP neural network}

\subsubsection{The establishment of BP neural network}

In building a neural network, the newff function is generally used, and its format is as follows: net $=$ newff(PR, $[\mathrm{S} 1, \mathrm{~S} 2, \ldots, \mathrm{SN}],\{\mathrm{TF} 1, \mathrm{TF} 2, \ldots, \mathrm{TFN}\}, \mathrm{BTF})$

In the above formula, net is the final generated neural network, $\mathrm{PR}$ is an $\mathrm{R} \times 2$ matrix to define the minimum and maximum values of $\mathrm{R}$ input vectors; $\mathrm{S}$ is the number of neurons in the $\mathrm{N}$ layer; $\mathrm{TF}$ is the transfer function; $\mathrm{BTF}$ is the training function.

A total of 9 different indicators are selected in this

$$
Y_{i j}=\frac{X_{\max }-X_{i j}}{X_{\max }-X_{\min }} \quad \text { Negative index }
$$

article, so there are 9 neurons in the input layer of the network, the output result is the final $\mathrm{Y}$ value, and the output layer has a total of one neuron. To determine the number of neurons in the hidden layer, there is currently no ideal set of models to solve this problem, because it is closely related to the input, output and problem requirements of this model, and it can only be done according to empirical formulas. Preliminarily determined, the formula is:

$$
N_{H}=\sqrt{N_{1} \times N_{0}}+N_{p} / 2
$$

In the above formula, $N_{H}$ is the number of neurons in the hidden layer; $N_{0}$ is the number of neurons in the input layer; $N_{1}$ is the number of neurons in the output layer; $N_{p}$ is the number of training samples.

By changing the training situation and error of the number of neurons in the hidden layer several times, the effect is best when the number of neurons in the hidden layer is 6 , so the entire neuron network structure is 
$9 \times 6 \times 1$ (Figure 2$)$.

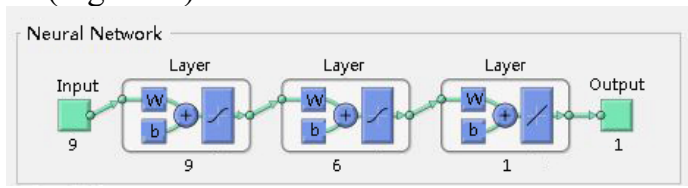

Figure 2 Neuron network structure

\subsubsection{Training of BP neural network}

Input the training data and test data into the neural network model, using Sigmoid as the activation function. The main parameters of the code are as follows:
inputWeights $=$ net.IW $\{2,1\}$;

inputbias $=$ net.b $\{1\}$; layerWeights $=$ net. $\operatorname{LW}\{2,1\}$; layerbias $=$ net. $\mathrm{b}\{2\}$; net.trainParam. show $=50$; net.trainParam. $1 \mathrm{r}=0.0$ 01 ;net.trainParam.mc $=0.9$; net.trainParam. epochs $=50000$; net.trainParam.goal $=0.00001$;

Then the training data is performed. When the final output error meets the requirements, the network is saved, and the normalized sample data of each index value in Zhengzhou City at the end of 2013-2017 is input to obtain the training results (Table 4) and the error graph (Figure 3).

Table 4 BP neural network training results

\begin{tabular}{lccccc}
\hline Years & 2013 & 2014 & 2015 & 2016 & 2017 \\
\hline $\begin{array}{c}\text { Evaluation } \\
\text { Results }\end{array}$ & 0.3039 & 0.5118 & 0.6189 & 0.6914 & 0.8509 \\
\hline
\end{tabular}

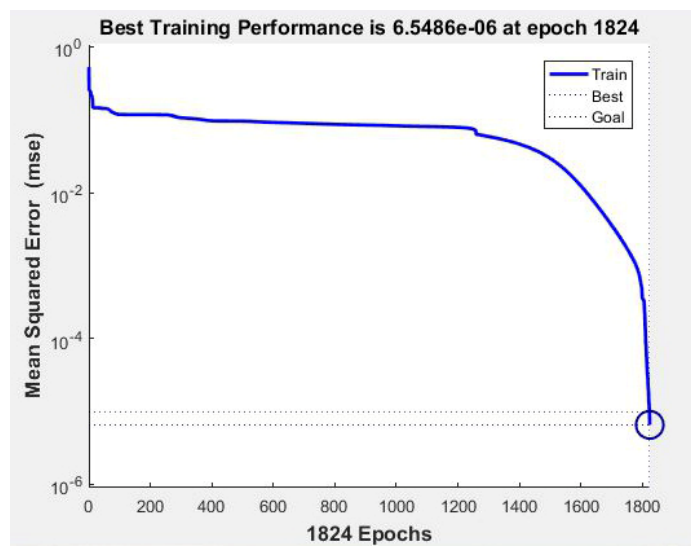

Figure 3 Errors of BP neural network land intensive evaluation results in Zhengzhou in 2017

\section{Results \& Discussion}

From the above results, it can be seen that the intensive use of land in Zhengzhou has been on the rise in the past five years, and the gradual transition from moderate use to intensive use shows the rapid development of Zhengzhou in the past few years. Among them, the degree of land intensification in 2014 and 2017 has been significantly accelerated, and the evaluation results have increased by 0.2079 and 0.1595 respectively compared with the previous year, indicating that the land use potential of Zhengzhou City is constantly being developed, and the city's functional areas are constantly improving, and the city scale effect Began to highlight. Among them, the economic benefits of land agglomeration and the economic supply capacity of land continue to develop in a coordinated manner; the infrastructure of various parts of the city has been continuously strengthened; the degree of environmental friendliness has continued to rise; the city's GDP has steadily increased; However, the overall level of land use in Zhengzhou is still in a relatively preliminary state of intensive use, and there is still a lot of room for development in the future. In the following development process, it should be noted that while increasing the intensive use of land, it should also take into account the economy. Development and environmental protection should coexist harmoniously, the problem of functional decline caused by the excessive use of land in the central area of the city, and the problem of urban malformation caused by the uneven development of the entire city.

\subsection{Make full use of urban underground space}

With the further development of urbanization, large and medium-sized cities are currently actively constructing a series of underground facilities such as subways, which is a manifestation of a city's development at a deeper level. Judging from the current situation in Zhengzhou, subway construction is far behind cities of the same level, such as Chengdu, Wuhan, and Xi'an. Only Metro Line 1 and Metro Line 2 are open to traffic, which will relatively restrict population flow and cause uneven urban land development.It is also necessary to increase the construction of underground shopping malls and underground parking lots that occupy a large amount of land on the ground to save land resources and effectively alleviate traffic congestion and parking difficulties.

\subsection{Strengthen ecological construction}

Today's urban development cannot blindly focus on economic interests, but must also ensure that the people have a healthy living environment. From historical experience, it is not advisable to sacrifice the ecological environment to carry out urban economic construction. At present, although the per capita green area of Zhengzhou City is at the mid-to-upper level of cities at the same level, most of them are in the suburbs and rural areas. Appropriately increasing the park green area in the central area of the city is an effective way to alleviate environmental problems. 


\subsection{Centralized establishment of industrial parks}

The centralized establishment of industrial parks, on the one hand, can release scattered large amounts of land in urban areas, so as to better construct and use these land resources. On the other hand, because the factories in these urban areas will generate a lot of noise and other pollution, it will largely Affect the lives and work of people in urban areas. The centralized establishment of industrial parks in suburban areas can not only facilitate unified management, but also promote the economic development of suburban areas. The government should guide and provide policy support to encourage factory relocation, optimize the allocation of land resources, and maximize and optimize multiple benefits.

\section{Conclusions}

The evaluation of the intensive use of urban land is a complex and highly comprehensive issue. It not only needs to be described from the general macro level, but also requires quantitative analysis of the details of each part.

(1) Through the use of BP neural network to evaluate the intensive use of land, compared with the intensive evaluation of the traditional method, its self-learning ability is strong, and it can continuously conduct self-learning after training a large number of sample data to automatically modify the weights and correctly map the data. The non-linear relationship between them greatly reduces human subjective factors, makes the evaluation process simple and fast, and the evaluation results are objective and fair.

(2) The indicators selected in this paper are the entire city as an individual and the urban built-up area as an individual respectively. The evaluations are made from the three aspects of land input intensity, land use intensity and land output benefits. The results show that Zhengzhou City from 2013 to 2017 The degree of intensive use of land continues to increase, but we must be wary of the imbalance of urban land development and the over-use of land.

(3) For the selection of evaluation indicators, there will be different choices for different regions. I have referred to a large amount of literature and have not been able to find a uniform and clear standard. Different researchers have their own methods for selecting evaluation indicators. Therefore, this article can only evaluate 9 indicators of Zhengzhou City based on the existing data analysis and previous studies. This is the shortcoming of the existing research on the land intensive evaluation system, and I hope it can be improved in the future research.

\section{References}

1. Li Wenli. Evaluation of Land Intensive Utilization in Xi'an [D]. Xi'an: Master's Thesis of Chang'an
University, 2017.

2. Jiang Zongli. Introduction to Artificial Neural Networks [M]. Beijing: Higher Education Press, 2003, 1-10.

3. Chang Qing, Wang Yanglin, Wu Jiansheng, et al. Artificial neural network judgment of the degree of urban land intensive use $[\mathrm{J}]$. China Land Science, 2007, 21(4): 26-31.

4. Li Huan, Xu Jianchun, Li Cuizhen, et al. Evaluation of Land Intensive Use in Development Zones Based on BP Artificial Neural Network-Taking Zhejiang Province as an Example [J]. Regional Research and Development, 2011, 30(4): $122-$ 126.

5. Zhu Hongmei, Zhou Ziying, Huang Chun, et al. The application of BP artificial neural network in the evaluation of urban land intensive use-Taking Changsha as an example [J]. Economic Geography, 2009, 29(5): 836-839

6. Chen Kun, Wang Changquan, Zhao Xiaorong, et al. Evaluation of soil suitability based on BP neural network- Taking the resettlement area of Gale of Xiluodu Hydropower Station as an example [J]. Southwest Agricultural Journal, 2009, 22(5): 14101415.

7. Li Huan, $\mathrm{Xu}$ Jianchun, $\mathrm{Xu}$ Zhiyuan, et al. Application Research of BP Artificial Neural Network in Land Intensive Use Evaluation_-Taking Suichang Industrial Park in Zhejiang Province as an Example [J]. Chinese Agricultural Science Bulletin, 2011, 27 (6) ): 447-450.

8. Chang Qing, Wang Yanglin, Wu Jiansheng, et al. The artificial neural network determination of the degree of urban land intensive use-taking Shenzhen as an example [J]. China Land Science, 2007, 21(4): 26-31.

9. Lin Jian, Chen Qihui, Jin Qiongyao. How should land be used-the connotation and index evaluation of urban land intensive use [J]. China Land, 2004, (11): 5-8.

10. Zhang Xuguang. Intensive use and evaluation of urban land in my country [D]. Xi'an University of Architecture and Technology, 2005: 35.

11. Li Shuangcheng, Zheng Du. The application progress of artificial neural network models in geoscience research [J]. Advances in Earth Science, 2003, 18 (1): 68-78.

12. He Fang, Wu Zhengxun. Summary and analysis of research on intensive use of urban land at home and abroad [J]. Land Economy, 2002, (3): 35-36. 